\title{
Putting the People in Science: Beginning My Career as a Science Communicator
}

\section{Scott Hershberger}

My favorite subject in school was always math. I was fascinated by fractals and the Fibonacci sequence, inspired by infinity and imaginary numbers. In elementary school, I memorized $\pi$ to 314 decimal places. As I grew older, I found more reasons to love math: its structure, its universality, the astonishing connections between seemingly unrelated ideas. Coupled with physics, I saw math as a window into the fundamental nature of the universe, which to me made it the subject most worth studying. I naively saw science, especially math, as absolute truth, isolated from the foibles of humanity.

When I entered college, I confidently declared a double major in math and physics, eager to learn as much as possible in both areas. I assumed at first that I would pursue a PhD in one of those fields, but as I advanced through my undergraduate years, my perspective shifted. I came to understand that science cannot-and should not-be pursued in isolation from the rest of society. And I resolved to dedicate my career to building bridges of dialogue between scientists and mathematicians and the public.

After writing a few news stories about science for my university's communications department, I applied to a host of science writing internships for my first summer after graduation. To my surprise and delight, I was placed at Scientific American through the AAAS Mass Media Fellowship

Scott Hershberger is the 2020 AMS Mass Media Fellow.

More information on the AMS Mass Media Fellowship can be found here: https://www.ams.org/programs/ams-fe11owships/media-fel1ow /massmediafel1ow The 2021 Mass Media Fellowship application deadline is January 1, 2021.

For permission to reprint this article, please contact: reprint-permission aams.org.

DOI: https://dx.doi.org/10.1090/noti2209 program, joining a class of 28 scientists who spent 10 weeks as science journalists at media outlets across the country.

The AAAS kicked off the summer with a three-day online orientation that included a crash course in science journalism, and then we were set loose (remotely) in our newsrooms. One of only two undergraduates in my cohort of fellows, I began with an unhealthy dose of imposter syndrome. Yet as I dove into a story on a new algorithm for ocean search-and-rescue operations, that feeling quickly dissolved. My understanding of the mathematical principles underlying differential equations helped me concisely convey the essence of the highly technical research. I soon moved on to stories about migrating animals, black holes, and more.

As I progressed through the summer, I found that studying math in college had prepared me well to report on dense scientific papers. Digesting unfamiliar jargon in fields I knew next to nothing about required breaking ideas into smaller chunks, understanding each chunk individually, and then seeing how they fit together-the same strategy that I applied countless times in math classes. Years of writing proofs had taught me to pay attention to details and to make implicit assumptions explicit, both invaluable skills in journalism. In fact, while reporting on two published studies, I spotted subtle mathematical typos that had slipped past the papers' authors and editors. But not everything about conducting math research carries over to crafting news stories.

In academia, we are taught to remove ourselves from our writing, to present our research as impartial and independent of us. In journalism, by contrast, the human element forms a key part of any story. Details about the struggles scientists faced during the research process or their emotional reactions upon seeing their results make science relatable to a broader audience. This summer I learned how 


\section{AMS COMMUNICATION}

to elicit such imagery in interviews and weave it into my writing. From the physicists who measured the lifetime of neutrons by cleverly repurposing old spacecraft data to the archaeologists who "quietly jumped up and down with excitement" upon receiving a rock sample that would reveal the origins of Stonehenge's stones, the story of science is the story of scientists.

I intentionally sought out a wide range of projects at Scientific American: fast-turnaround stories on single studies, longer pieces adding broader context to recent research, and short podcasts. In addition to writing about math and physics, I took the opportunity to explore topics including archaeology, the environment, and biotechnology. My most ambitious piece was a feature story on society's collective memory of the 1918-19 flu pandemic and the implications for how we will collectively remember (or forget) COVID19 decades from now. After the story was published online, the editors chose it for publication in the November print issue of the magazine.

In my 10 weeks at Scientific American, I interviewed about 70 scientists and mathematicians from around the world and wrote 19 stories totaling more than 16,000 words. Despite never meeting any of my coworkers in person, weekly videoconferences with the news editors and occasional virtual happy hours helped me feel connected to them. I got great mentorship and career advice, and the skills I honed will serve me for my whole career. I am so grateful to the AAAS and the AMS for helping me jump-start my journey.

I spent this fall applying my storytelling skills to institutional science communication as a science writing intern at Fermilab. Now, I am joining the AMS team as the Communications and Outreach Content Specialist. All my experiences so far have reaffirmed my decision to apply my knowledge of physics and math to science communication. Scientific advances have solved countless societal problems and created others. Now more than ever, we need to cultivate a society in dialogue with the process of science, and I am excited to do my part. Math may be a window into the fundamental nature of the universe-but more importantly, it is a window into the human world that we all share.

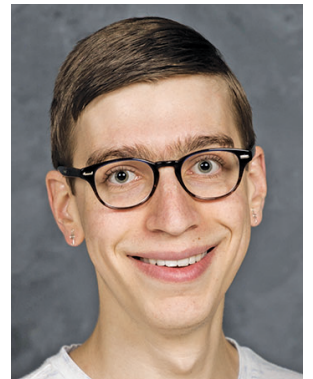

Scott Hershberger

\section{Credits}

Author photo is courtesy of Jiyoon Kang.

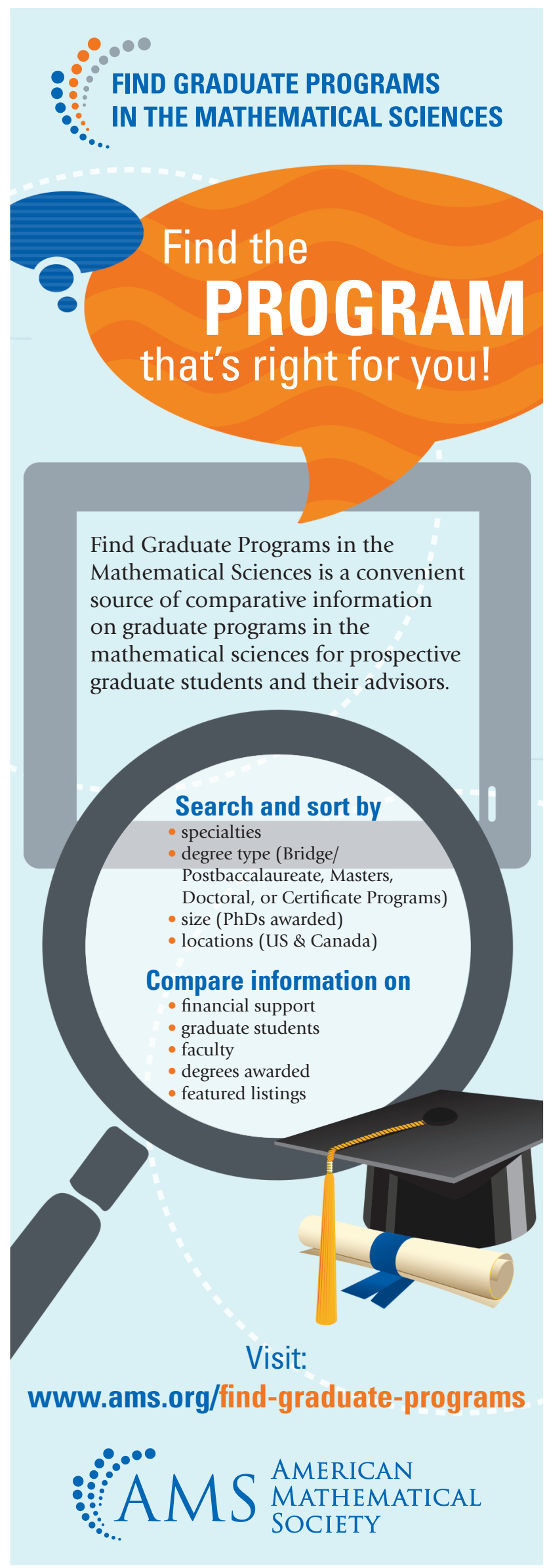

